\title{
Inappropriateness of fresh frozen plasma for abnormal coagulation tests
}

\author{
${ }^{1} \mathrm{~S}$ Pybus, ${ }^{1} \mathrm{~A}$ MacCormac, ${ }^{2} \mathrm{~A}$ Houghton, ${ }^{3} \mathrm{~V}$ Martlew, ${ }^{3} \mathrm{~J}$ Thachil
}

${ }^{1}$ Medical Student, School of Medicine, University of Liverpool; ${ }^{2}$ Specialist Transfusion Practitioner, Department of Transfusion Science, Royal Liverpool University Hospital; ${ }^{3}$ Consultant Haematologist, Department of Haematology, Royal Liverpool University Hospital, Liverpool, UK

\section{ABSTRACT}

Background: There is increasing evidence to suggest that the use of fresh frozen plasma (FFP) as a prophylaxis to bleeding is ineffective. However, a high proportion of FFP transfusions still occur in non-bleeding patients despite the high risk of adverse events. The aim of the study was to assess compliance with current prophylactic FFP guidelines at a large tertiary centre.

Methods: Data were collected retrospectively over a 16-month period from May 2010 to August 201I. Information collected included patient characteristics, indications for and details of FFP use, and the ordering of coagulation screens before and after transfusion.

Results: Over this period, FFP was used in a total of 573 transfusion episodes, 88 of which were prophylactic. This use deviated from the British Committee for Standards in Haematology guidelines in three main areas: indications for FFP use (89\%), dose prescribed (49\%) and the measurement of prothrombin time (PT) and activated partial thromboplastin time (APTT) after transfusion (66\%).

Conclusions: There were no significant differences in compliance with guidelines between different hospital departments, suggesting a culture of widespread inappropriate FFP use and a general lack of understanding among clinicians. Physician training and increased enforcement of existing guidelines could reduce FFP usage and expenditure.

KEYWORDS Coagulation, plasma, transfusion

DECLARATION OF INTERESTS No conflicts of interest declared.
Correspondence to J Thachil, Department of Haematology, Royal Liverpool University Hospital, Prescot Street, Liverpool L7 8XP

tel. +44 (0)15I 7064322 e-mail jeckothachil@yahoo.co.uk

\section{INTRODUCTION}

Fresh frozen plasma (FFP) has been used in the prophylaxis and treatment of patients with coagulopathy and bleeding. However, in recent years, there is an increasing evidence base to suggest that FFP use as prophylaxis in patients with abnormal coagulation tests who are not bleeding is ineffective and often inappropriate.' Despite this, the levels of FFP use in the UK have not fallen and an estimated $33-43 \%$ of transfusions have been noted to occur in cases where bleeding is not suspected. ${ }^{2,3}$

The use of plasma and plasma-derived products should always follow a careful assessment of anticipated benefit vs risk. Although pathogen-inactivated products have reduced the risk of transfusion-transmitted infections, other adverse effects like transfusion-related acute lung injury (TRALI) and transfusion-associated circulatory overload continue to pose problems in those who receive FFP. 4.5 Transfusion-related acute lung injury is the leading cause of mortality following blood transfusion, with an estimated prevalence of $8 \%$ among the intensive care population. ${ }^{6-8}$ Such risks associated with this blood product highlight the importance of adhering to guidelines outlining the appropriate use of FFP and the role of coagulation testing both before and after transfusion.

Although the British Committee for Standards in Haematology ( $\mathrm{BCSH}$ ) guidelines describe only a limited role for FFP in liver biopsy, it is often used prior to other invasive procedures, such as laparotomy, central line insertion and endoscopy. ${ }^{3}$ This is despite some previous studies demonstrating that such procedures can be safely performed in patients with an abnormal coagulation screen. ${ }^{9}$ Although prothrombin time (PT) and activated partial thromboplastin time (APTT) may be useful in identifying individuals who may have inherited bleeding disorders, they are not accurate predictors of bleeding during invasive procedures or surgery. ${ }^{10-12}$ However PT and APTT are currently the only routinely measured indicators of coagulation with which clinicians can assess response to prophylactic FFP transfusion.

This paper aims to explore the use of FFP as a prophylactic measure to correct abnormal coagulation tests at a large tertiary centre. Therefore a key aim is to determine physician compliance in ordering coagulation 
screens before and after transfusion, as required by current guidelines. ${ }^{13}$ We will describe the indications stated for FFP use, and analyse how these patterns compare to the rest of the UK and other reports of inappropriate use from previous years. ${ }^{3}$

\section{METHODS}

Data were collected retrospectively using a hospital database. We looked at records from a 16-month period, from I May 2010 to 30 August 20I I. It should be noted that this centre does not provide services in paediatrics, cardiothoracic surgery, obstetrics or gynaecology. The data collection followed the approval for the study from the regional audit committee. Patient reports for each transfusion episode were examined to determine inclusion or exclusion, using the criteria detailed below.

\section{Inclusion criteria}

I. Clear indication of FFP to be used as prophylaxis on patient request forms directly preceding transfusion episode.

2. Reports indicative of an invasive procedure having been performed within six hours after the transfusion episode.

\section{Exclusion criteria}

I. 'Bleeding' stated on any patient request form in the six hours prior to transfusion episode.

2. 'Plasmapheresis' or 'plasma exchange' on any patient request forms in the six hours prior to transfusion.

3. New onset decrease in haemoglobin below reference range for this Trust (below $133 \mathrm{~g} / \mathrm{L}$ for males or I $18 \mathrm{~g} / \mathrm{L}$ for females), within six hours prior to transfusion.

4. More than four units of FFP used and/or multiple transfusion episodes documented in a patient's recent clinical records. High volumes of transfusion indicate use in massive haemorrhage, while multiple transfusion episodes may indicate plasma exchange. In both these settings, plasma infusion has been shown to be extremely worthwhile.

The following information was extracted for each transfusion episode:

I. Patient characteristics, limited to sex and date of birth.

2. Specialty ward to which FFP was ordered.

3. Indication for FFP use, or in the absence of a clear indication, the related disease process.

4. Number of units of FFP used.

5. Date and time of FFP use.

6. PT and APTT recorded less than 24 hours prior to transfusion.
7. PT and APTT recorded less than eight hours after transfusion.

8. Patient death within 48 hours of transfusion.

Twenty-four hours was selected as an acceptable time frame for the measurement of a coagulation screen to assess the presence and severity of a coagulopathy before transfusion. Eight hours was established for the recording of a coagulation screen after transfusion as this is the half-life of factor VII, the shortest half-life of the procoagulant factors. ${ }^{14}$ The normal range for PT at this centre is 9-13 seconds, and 25-36 seconds for APTT. Finally, the data were analysed to determine the appropriateness of the transfusions by indication and to describe clinician compliance in monitoring coagulation before and after transfusion.

\section{RESULTS}

A total of 1,673 units of FFP were administered in 573 transfusion episodes over the 16-month period. Of these, 264 units (16\%) were used in 88 transfusion episodes (15.4\%) as prophylaxis to bleeding. The numbers of transfusion episodes and mean number of units of FFP administered by indication is given in Table I. In these 88 transfusion episodes, 49 treated males while 39 treated females. The median age of these patients was 56 years (range: 23-87 years). Three patients died within 48 hours of receiving FFP. Two were critical care patients, one with urosepsis and renal failure, and the other suffering from alcoholic liver disease (ALD). The third patient had chest drainage performed on a medical ward. The causes of these deaths could not be elucidated from the database used.

The distribution of indications for FFP use in different clinical settings is given in Table 2 . The majority of patients with an unknown indication for transfusion were from critical care $(n=13)$. This patient subset was typically noted to have either multiple organ failure or respiratory failure alone. However, suspected disseminated intravascular coagulation (DIC) and sepsis were also noted on patient request forms. One patient in this group had an initial PT of $107.8 \mathrm{~s}$, implying FFP use related to warfarin overdose. Unfortunately not enough information was available to determine a definitive indication for FFP transfusion.

In 87 of the transfusion episodes (total=88), PT was recorded prior to FFP transfusion. The anomalous transfusion case occurred in the emergency department as prophylaxis for pericardiocentesis and was excluded from the analysis of post-transfusion coagulation screens. The APTT was measured prior to transfusion in 82 of the remaining 87 transfusion episodes (94.3\%). However, PT and APTT were measured $\leq 8$ hours after transfusion 
TABLE I Numbers of transfusion episodes and mean number of units of FFP administered by indication

\begin{tabular}{|l|c|c|c|}
\hline Indication & $\begin{array}{c}\text { Number of transfusion } \\
\text { episodes }\end{array}$ & $\begin{array}{c}\text { Proportion of all } \\
\text { transfusion episodes }\end{array}$ & $\begin{array}{c}\text { Mean number of units of } \\
\text { FFP administered }\end{array}$ \\
\hline Unknown & 18 & $20.5 \%$ & 2.89 \\
\hline Pre-operative & 14 & $15.9 \%$ & 2.86 \\
\hline Ascitic drain & 11 & $12.5 \%$ & 2.73 \\
\hline Alcoholic liver disease & 10 & $11.4 \%$ & 2.90 \\
\hline Line insertion & 9 & $10.2 \%$ & 3.56 \\
\hline Other drain & 8 & $9.09 \%$ & 3.13 \\
\hline Biopsy & 6 & $6.82 \%$ & 3.67 \\
\hline Chest drain & 6 & $6.82 \%$ & 3.00 \\
\hline $\begin{array}{l}\text { Disseminated intravascular } \\
\text { coagulation }\end{array}$ & 3 & $3.41 \%$ & 3.33 \\
\hline Other & 3 & $3.41 \%$ & 2.00 \\
\hline
\end{tabular}

TABLE 2 Distribution of indications for FFP use by setting

\begin{tabular}{|c|c|c|c|c|c|}
\hline Indication & Medical ward & Critical care & Surgical ward & Post-op care & $\begin{array}{c}\text { Emergency } \\
\text { Department }\end{array}$ \\
\hline Unknown & 5 & 13 & 0 & 0 & 0 \\
\hline Pre-operative & 5 & I & 6 & 2 & 0 \\
\hline Ascitic drain & 7 & 3 & 1 & 0 & 0 \\
\hline $\begin{array}{l}\text { Alcoholic liver } \\
\text { disease }\end{array}$ & 5 & 3 & 0 & I & I \\
\hline Line insertion & 1 & 5 & $\mathrm{I}$ & 2 & 0 \\
\hline Other drain & 4 & I & 2 & 0 & 1 \\
\hline Biopsy & 6 & 0 & 0 & 0 & 0 \\
\hline Chest drain & 4 & 1 & 0 & 1 & 0 \\
\hline $\begin{array}{l}\text { Disseminated } \\
\text { intravascular } \\
\text { coagulation }\end{array}$ & 2 & 1 & 0 & 0 & 0 \\
\hline Other & I & I & I & 0 & 0 \\
\hline
\end{tabular}

in only 30 and 26 of the remaining 87 transfusions, respectively. There were no statistically significant differences between coagulation screen compliance levels for each indication $\left(\chi^{2}=6.00, p=0.740\right)$ (Figure I). However, patients undergoing ascitic drainage were the least likely to receive a post-transfusion coagulation screen $(9 \%)$ compared to $50 \%$ of patients with alcoholic liver disease and pre-operative patients.

The majority of FFP requests were made to medical wards (Figure 2). Use in gastroenterology predominated, making up almost half of transfusion episodes on medical wards (17 of 40). Indications stated for FFP use in gastroenterology were ascitic drains $(n=3)$, ALD-related $(n=3)$, biliary procedures $(n=3)$, chest drains $(n=2)$, liver biopsy $(n=2)$, pancreatic pseudocyst procedure $(n=2)$, pelvic drain $(n=I)$, and suspected DIC $(n=I)$. No significant differences were found in compliance with post-transfusion coagulation screens by location $\left(\chi^{2}=2.34, p=0.672\right)$.

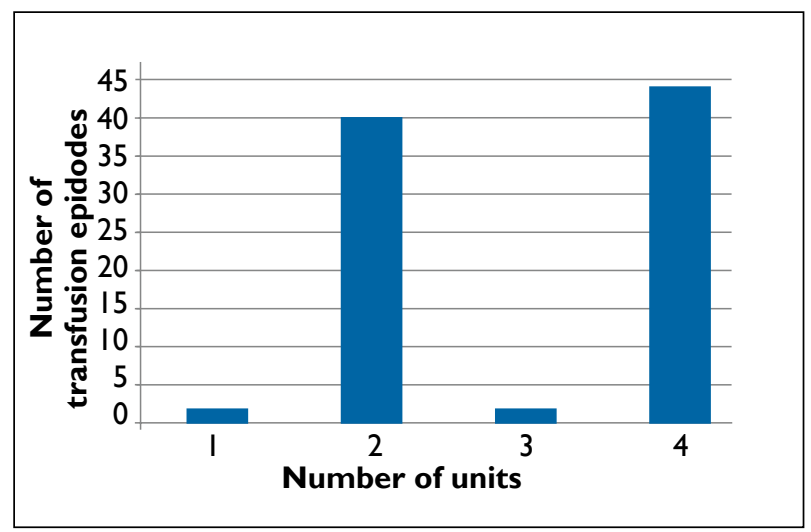

FIGURE I Number of units of FFP administered.

The numbers of transfusion episodes and mean number of units of FFP administered by setting is given in Table 3. A standard dose of FFP is considered to be $10-15 \mathrm{~mL} /$ $\mathrm{kg}$ with FFP packs averaging around $300 \mathrm{~mL}$. However 


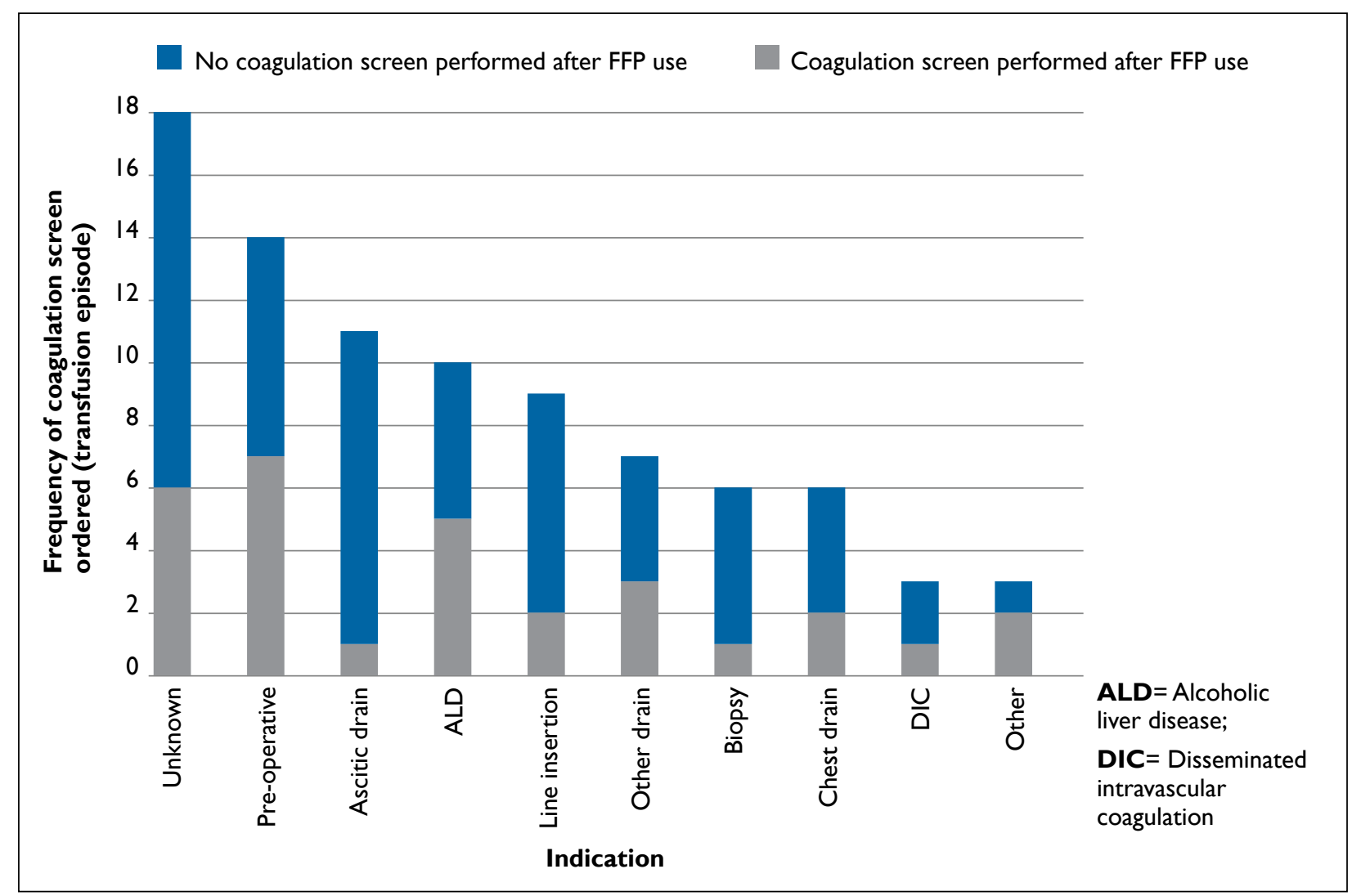

FIGURE 2 Compliance with coagulation screen after FFP use by indication.

$48 \%$ of transfusion episodes under study involved only one or two units, which is a sub-therapeutic dose for most adults (less than $30 \mathrm{~kg}$ ) (Figure 3). Where FFP is given, this must be at a therapeutic dose.

Of the 30 patients with a PT recorded after transfusion, 25 had a decrease in PT following FFP but only one returned to within normal limits. The remaining five patients had an increased PT following FFP. Of these patients, three had surgery, therefore an increased PT could be explained by development of sepsis or other surgical complications. In these 30 patients, 20 had a decreased APTT following FFP with four correcting to within normal limits. The characteristics of the patients where FFP led to correction of coagulation screen to within normal limits is given in Table 4. In one episode, there was no change in APTT after FFP and in five episodes, APTT had increased following transfusion. Again, three of these patients had surgery, therefore sepsis or other surgical complications could explain their increased APTT.

\section{DISCUSSION}

Despite an increasing volume of evidence challenging the prophylactic use of FFP, use outside current guidelines remains widespread. We found a lack of compliance with current guidelines in three main areas: indications for FFP use, dose prescribed, and the recording of a coagulation screen after transfusion.

The proportion of transfusion episodes for prophylaxis against bleeding at this centre (15\%) is lower than that

TABLE 3 Numbers of transfusion episodes and mean number of units of FFP administered by setting

\begin{tabular}{|l|c|c|c|}
\hline Setting & $\begin{array}{c}\text { Number of } \\
\text { transfusion episodes }\end{array}$ & $\begin{array}{c}\text { Proportion of all } \\
\text { transfusion episodes }\end{array}$ & $\begin{array}{c}\text { Mean number of units of } \\
\text { FFP administered }\end{array}$ \\
\hline Medical ward & 40 & $45.5 \%$ & 3.08 \\
\hline Critical care & 29 & $33.0 \%$ & 2.97 \\
\hline Surgical ward & 11 & $12.5 \%$ & 2.82 \\
\hline Post-operative care & 6 & $6.82 \%$ & 2.67 \\
\hline $\begin{array}{l}\text { Emergency } \\
\text { Department }\end{array}$ & 2 & $2.27 \%$ & 4.00 \\
\hline
\end{tabular}




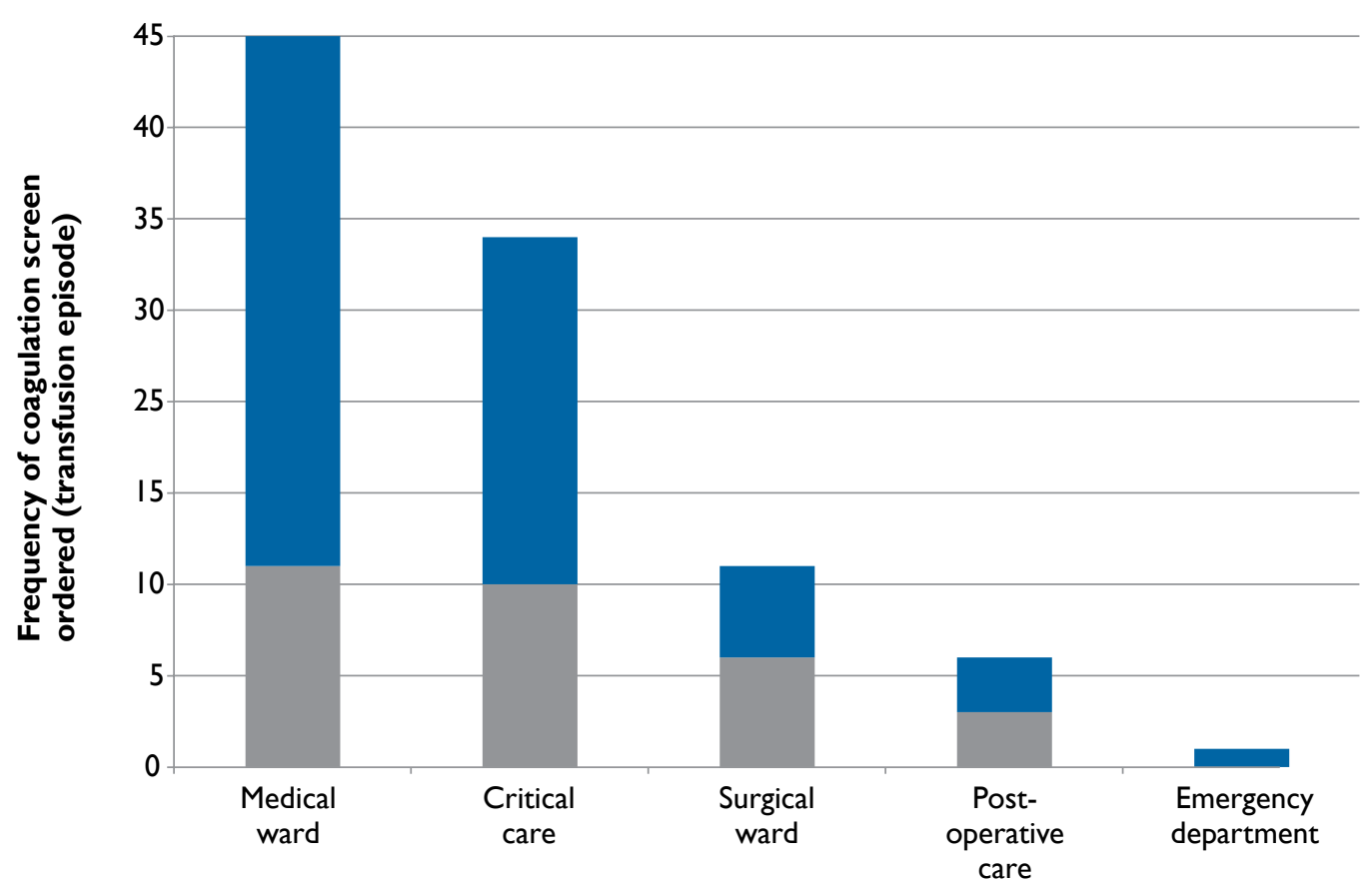

FIGURE 3 Compliance with coagulation screen after FFP use by location.

reported on a national level in 2008 (43\%). ${ }^{3}$ It appears that since 2008, inappropriate use of FFP in reversal of warfarin therapy has been curtailed. However, its use related to liver disease remains high, comprising $13 \%$ of transfusion episodes at this centre compared to the $19 \%$ previously reported. ${ }^{3}$ After accounting for the differences in patient population, the use of FFP in all other indications appears to have remained constant since 2008. A total of $89 \%$ of prophylactic transfusion episodes at this centre were for indications stated outside of those approved by the $\mathrm{BCSH} .{ }^{13}$ The remaining I I\% (related to ALD), may be within current guidelines if the transfusion had preceded liver biopsy. ${ }^{12}$ However, this is not supported by evidence as PT and APTT do not reflect the haemostatic state of patients with liver disease, implying that FFP prophylaxis may not always be necessary. ${ }^{12}$

The high number of prophylactic transfusion episodes occurring in critical care is also a matter of concern. Studies have shown that vitamin $\mathrm{K}$ deficiency is present in $25 \%$ of the intensive care population and is the most common cause of coagulopathy in this patient group. ${ }^{15,16}$ This can be treated by vitamin $\mathrm{K}$ supplementation which

TABLE 4 Characteristics of patients where FFP led to correction of coagulation screen to within normal limits. Analysis from one patient who normalised the PT and four patients who normalised the APTT

\begin{tabular}{|l|c|c|c|c|c|c|c|}
\hline $\begin{array}{l}\text { Corrected } \\
\text { measure }\end{array}$ & $\begin{array}{c}\text { PT prior } \\
\text { to FFP(s) }\end{array}$ & $\begin{array}{c}\text { PT after } \\
\text { FFP(s) }\end{array}$ & $\begin{array}{c}\text { APTT } \\
\text { prior to } \\
\text { FFP(s) }\end{array}$ & $\begin{array}{c}\text { APTT } \\
\text { after } \\
\text { FFP(s) }\end{array}$ & $\begin{array}{c}\text { Quantity } \\
\text { of FFP } \\
\text { received } \\
\text { (units) }\end{array}$ & Setting & Indication \\
\hline PT & 16.2 & 13.0 & 67.6 & 52.5 & 4 & Medical ward & $\begin{array}{c}\text { Hepatic abscess } \\
\text { drainage ('other drain') }\end{array}$ \\
\hline APTT & 24.5 & 19.2 & 43.8 & 33.3 & 4 & Critical care & $\begin{array}{c}\text { Abdominal drainage } \\
\text { related to pancreatitis } \\
\text { ('other drain') }\end{array}$ \\
\hline APTT & 19.2 & 14.2 & 44.2 & 30.6 & 4 & Medical ward & Emergency \\
\hline APTT & 51.0 & 25.7 & 42.5 & 32.5 & 4 & ALD related ('ALD') \\
\hline APTT & 22.4 & 16.7 & 38.0 & 32.9 & 2 & Critical care & Sepsis related \\
('unknown')
\end{tabular}


may prevent the need for FFP at a later stage. ${ }^{17}$ Despite this, many centres do not routinely give vitamin $\mathrm{K}$ to critical care patients.

A standard dose of FFP is considered to be $10-15 \mathrm{~mL} /$ $\mathrm{kg}$ with FFP packs averaging around $300 \mathrm{~mL} .{ }^{18}$ However, we noted that many of the patients received a subtherapeutic dose of FFP. Despite the low dose, even a small amount of plasma can be considered to expose the patient to risks of adverse reaction without therapeutic benefit. Three patients died within 48 hours of receiving a prophylactic transfusion. Although the role of FFP in these deaths cannot be confirmed, it is a reminder of the high risks associated with its use.

There is also poor compliance with guidelines in performing coagulation screens after FFP transfusion. Previous studies have demonstrated a lack of understanding among clinicians, with many believing that FFP will correct PT and APTT and therefore reduce the risk of bleeding. ${ }^{18}$ However little evidence exists to support either of these assumptions.' Where FFP transfusion is used to correct coagulopathy, PT and APTT should be measured following transfusion to determine the extent of any improvement before the planned procedure takes place. However, only $34.5 \%$ of patients had post-transfusion coagulation screening performed. There were no significant differences in compliance with the post-transfusion coagulation screening between each indication, or between different locations, suggesting a culture of widespread inappropriate use of FFP among clinicians, and their general lack of understanding.

The financial implications of inappropriate FFP use are also significant. It costs this Trust $£ 27.66$ per unit. Therefore the cost incurred from FFP transfusion outside current guidelines in this study can be estimated at $\notin 6,500$. Although the quoted price is purely the cost per bag, there are several other factors including manpower, laboratory equipment and reagents and administrative costs in addition to the hospital staff and bed time which has not been taken into consideration but will add much more to the 'total' cost for FFP use. This was highlighted in a recent paper by Shander and colleagues. Using an activity-based costing $(A B C)$ model, they showed that blood costs have been underestimated and stringent control of blood utilisation being necessary to reduce expenditure. ${ }^{19}$ In this context, it is also important to note that FFP is a limited resource and therefore should be used with care and within existing guidelines. In addition, although FFP contains several of the coagulation factors, virus-inactivated plasma-derived concentrates have been developed for the management of patients who have congenital or acquired bleeding disorders (except factor $\mathrm{V}$ deficiency). ${ }^{20}$ For this reason, in many countries, except for the extremely rare coagulation factor $V$ deficiency, all other patients requiring clotting factors are given specific concentrates like factor VIII or IX or prothrombin complex concentrates which contains factors II, VII, IX and X.

Our study suggests that FFP transfusion does not reliably correct PT and APTT values. However due to the high proportion of missing coagulation screens, robust conclusions cannot be drawn about the effectiveness of FFP in correcting PT and APTT. Another limitation of this study is the use of patient request forms for data collection. The data were often of poor quality and difficult to interpret. As a result, the number of transfusions in non-bleeding patients not receiving plasma exchange but of an unknown indication is high (20\%).

\section{CONCLUSION}

Fresh frozen plasma is associated with higher rates of inappropriate use than any other blood product. Several studies have indicated that inadequate training is to blame for this. A reluctance to adhere to the guidelines has also been identified as a contributing factor to the high number of inappropriate FFP transfusions, with over $46.5 \%$ of physicians being reported as non-compliant in one study. ${ }^{21,22}$ One interventional study reported an $80 \%$ reduction in FFP usage and reduced inpatient mortality following physician training and enforcement of preexisting FFP guidelines. ${ }^{23}$ Such measures could be of benefit in this centre. More must be done to ensure that FFP transfusion occurs within current guidelines, especially those regarding indication, dose, and repeated coagulation screening. Recent studies have attempted this in different settings (including paediatrics) and confirmed the ongoing inappropriate use of FFP for abnormal coagulation screening. ${ }^{24,25}$ 


\section{REFERENCES}

I Stanworth SJ, Brunskill SJ, Hyde C] et al. Is fresh frozen plasma clinically effective? A systematic review of randomized controlled trials. Br J Haematol 2004; I 26: I 39-52. http://dx.doi.org/ I0. I I I I/ j.I365-2 I4I.2004.04973.x

2 Vlaar AP, in der Maur AL, Binnekade JM et al.A survey of physicians' reasons to transfuse plasma and platelets in the critically ill: a prospective single-centre cohort study. Transfus Med 2009; 19:207-12. http://dx.doi.org/I0. I I I //j.| 365-3 |48.2009.00928.x

3 Stanworth SJ, Grant-Casey J, Lowe D et al. The use of freshfrozen plasma in England: high levels of inappropriate use in adults and children. Transfusion 20II; 5I:62-70. http://dx.doi. org/I0.I III/j.I537-2995.20I0.02798.x

4 Kor DJ, Stubbs JR, Gajic O. Perioperative coagulation management - fresh frozen plasma. Best Pract Res Clin Anaesthesiol 2010; 24:5I64. http://dx.doi.org//0.1016/j.bpa.2009.09.007

5 Marik PE, Corwin HL. Acute lung injury following blood transfusion: expanding the definition. Crit Care Med 2008; 36:3080 4. http://dx.doi.org//0.1097/CCM.0b013e3/818c3801

6 Gajic O, Rana R, Winters JL et al. Transfusion-related acute lung injury in the critically ill: prospective nested case-control study. Am J Respir Crit Care Med 2007; I76:886-9I. http://dx.doi.org// 0.I I64/ rccm.200702-27IOC

7 Triulzi DJ.Transfusion-related acute lung injury: current concepts for the clinician. Anesth and Analg 2009; 108:770-6. http://dx.doi. org/10.1213/ane.0b013e31819029b2

8 Stanworth SJ, Hyde CJ, Murphy MF. Evidence for indications of fresh frozen plasma. Transfus Clin Biol 2007; 14:55I-6. http://dx.doi. org/I0.1016/j.tracli.2008.03.008

9 Gajic O, Dzik WH, Toy P. Fresh frozen plasma and platelet transfusion for nonbleeding patients in the intensive care unit: benefit or harm? Crit Care Med 2006; 34:SI70-3. http://dx.doi. org/I0.1097/0I.CCM.00002/4288.88308.26

10 Segal JB, Dzik WH. Paucity of studies to support that abnormal coagulation test results predict bleeding in the setting of invasive procedures: an evidence-based review. Transfusion 2005; 45:141325. http://dx.doi.org/I0.I I I I/j. I537-2995.2005.00546.x

II Eckman MH, Erban JK, Singh SK et al. Screening for the risk for bleeding or thrombosis. Ann Intern Med 2003; I38:WI5-24.

12 Lisman T, Caldwell SH, Burroughs AK et al. Hemostasis and thrombosis in patients with liver disease: the ups and downs. J Hepatol 2010; 53:362-71. http://dx.doi.org//0.1016/j.jhep.2010.01.042

I3 O'Shaughnessy DF, Atterbury C, Bolton Maggs $P$ et al. Guidelines for the use of fresh-frozen plasma, cryoprecipitate and cryosupernatant. $\mathrm{Br} J$ Haematol 2004; I26:I I-28. http://dx.doi. org/I0.IIII/j.I365-2|14I.2004.04972.x
I4 Benzon HT, Avram MJ, Benzon HA et al. Factor VII levels and international normalized ratios in the early phase of warfarin therapy. Anesthesiology 2010; II2:298-304. http://dx.doi. org/I0.1097/ALN.0b0I3e318I ca6cfo

I5 Crowther MA, McDonald E, Johnston M et al.Vitamin K deficiency and D-dimer levels in the intensive care unit: a prospective cohort study. Blood Coagul Fibrinolysis 2002; 13:49-52.

16 Chakraverty R, Davidson S, Peggs $\mathrm{K}$ et al. The incidence and cause of coagulopathies in an intensive care population. $\mathrm{Br}$ J Haematol 1996; 93:460-3. http://dx.doi.org//0.1046/j.1365-2141.1996.5I0I050.x

17 O'Shaughnessy D, Allen C, Woodcock T et al. Echis time, undercarboxylated prothrombin and vitamin $\mathrm{K}$ status in intensive care patients. Clin Lab Haematol 2003; 25:397-404. http://dx.doi. org/10.1046/j.014I-9854.2003.00547.x

I8 Stanworth SJ.The evidence-based use of FFP and cryoprecipitate for abnormalities of coagulation tests and clinical coagulopathy. Hematology Am Soc Hematol Educ Program 2007:179-86. http:// dx.doi.org/I0.I I82/asheducation-2007.I.I79

19 Shander A, Hofmann A, Ozawa S et al.Activity-based costs of blood transfusions in surgical patients at four hospitals. Transfusion 2010; 50:753-65. http://dx.doi.org//0.I I I //j.I537-2995.2009.025 I8.x

20 Burnouf T. Modern plasma fractionation. Transfus Med Rev 2007; 21:I0I-17. http://dx.doi.org/I0.1016/j.tmrv.2006.II.001

21 Lauzier F, Cook D, Griffith $L$ et al. Fresh frozen plasma transfusion in critically ill patients. Crit Care Med 2007; 35:1655-9. http://dx. doi.org/I0.I097/0I.CCM.0000269370.592/4.97

22 Chang CS, Lin YC, Wu YC et al. The effects of a computerized transfusion decision support system on physician compliance and its appropriateness for fresh frozen plasma use in a medical center. Am J Clin Pathol 20II; 135:4I7-22. http://dx.doi.org/I0.1309/ AJCPOECFNHMGJ8EA

23 Tavares $M$, DiQuattro $P$, Nolette $N$ et al. Reduction in plasma transfusion after enforcement of transfusion guidelines. Transfusion 20I I; 5I:754-6I. http://dx.doi.org/I0.II I I/j.I537-2995.20I0.02900.x

24 Puetz J,Witmer C, Huang YS et al.Widespread use of fresh frozen plasma in US children's hospitals despite limited evidence demonstrating a beneficial effect. J Pediatr 2012; 160:210-5. http:// dx.doi.org/I0.1016/j.jpeds.201 I.08.013

25 Kozek-Langenecker S, Sørensen B, Hess JR et al. Clinical effectiveness of fresh frozen plasma compared with fibrinogen concentrate: a systematic review. Crit Care 20I I; I 5:R239. http://dx.doi.org/I0.I I86/ ccl0488

\section{CONFERENCING AND EVENTS}

The Royal College of Physicians of Edinburgh has a unique blend of rooms providing the perfect location for your conference, meeting or event. The Victorian Great Hall, galleried New Library and the Georgian Cullen Suite are wonderful settings for dinners and receptions. The modern Conference Centre seats up to 300 people in raked seating and is complemented by breakout rooms seating from 10 to 150 people, a keypad voting system and video conferencing. The College provides a stunning setting for weddings and receptions and is licensed for both civil and religious ceremonies. Discounts are available for Fellows and Members, medical conferences and charities.

For more information or for a quotation, please contact the Events Team on +44 (0) I3I 225 7324; email events@rcpe.ac.uk or visit http://www.rcpe-venue.co.uk

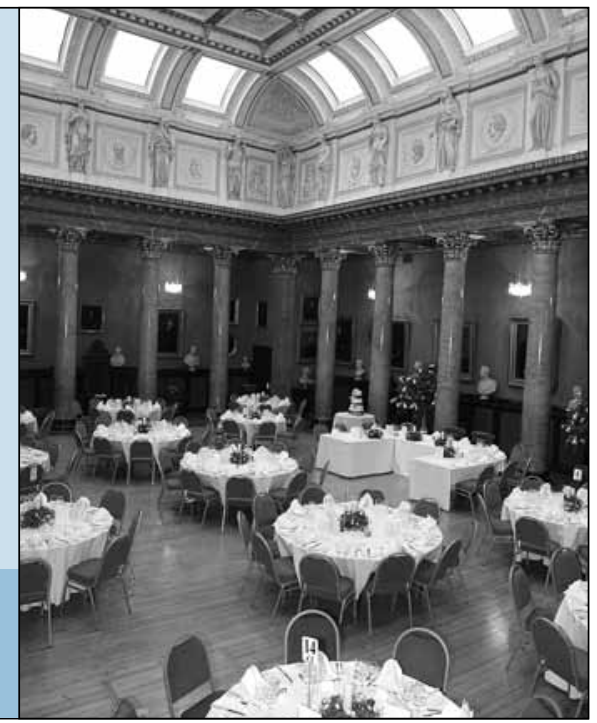

